\title{
Photovoltaic Field-Effect Photodiodes Based on Double van der Waals
}

\section{Heterojunctions}

Yurong Jiang, Ruiqi Wang, Xueping Li, Zinan Ma, Lin Li, Jian Su,Yong Yan, Xiaohui Song, Congxin Xia*

School of Physics, Henan Key Laboratory of Photovoltaic Materials, Henan Normal University, Xinxiang, 453007, China

Email: xiacongxin@htu.edu.cn

Figure S 1a presents the top view atomic force microscope (AFM) image of PVFED constructed by $\mathrm{WSe}_{2}$ and $\mathrm{MoS}_{2}$ layered materials. Figure $\mathrm{S} 1 \mathrm{~b}, \mathrm{c}$ and d show the height of top $\mathrm{WSe}_{2}$, middle $\mathrm{MoS}_{2}$ and bottom $\mathrm{WSe}_{2}$ are $41 \mathrm{~nm}, 12 \mathrm{~nm}$ and $8 \mathrm{~nm}$, respectively.
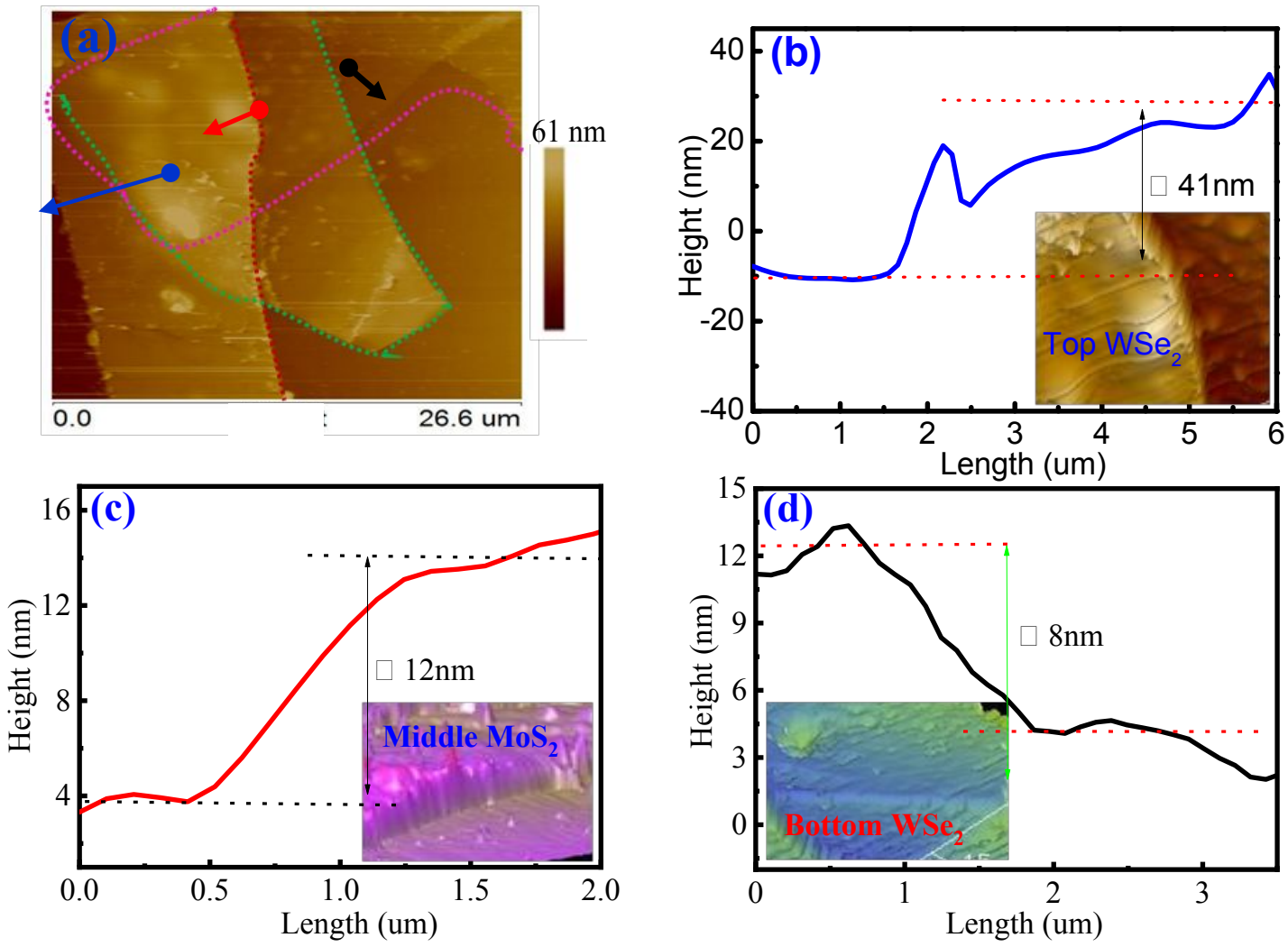

Figure S1 (a) AFM image of $\mathrm{WSe}_{2} / \mathrm{MoS}_{2} / \mathrm{WSe}_{2}$ heterostructures. (b) Height profile of top $\mathrm{WSe}_{2}$ nanosheet. (c) Height profile of middle $\mathrm{MoS}_{2}$. (d) Height profile of bottom $\mathrm{WSe}_{2}$.

From Figure S 2a can be seen, compared to $\mathrm{WSe}_{2}$ or $\mathrm{MoS}_{2}$ layer, the heterojunctions possess the high light absorption ability around the short wavelength and a lower absorption ability at the longer wavelength. Figure $2 \mathrm{~b}$ shows a cutoff wavelength of around $800 \mathrm{~nm}$ arising from the band gap of $1.55 \mathrm{eV}$ of $\mathrm{WSe}_{2}$. It would be suggested the indirect band gap properties of 8-41 nm thick nanoflakes. 

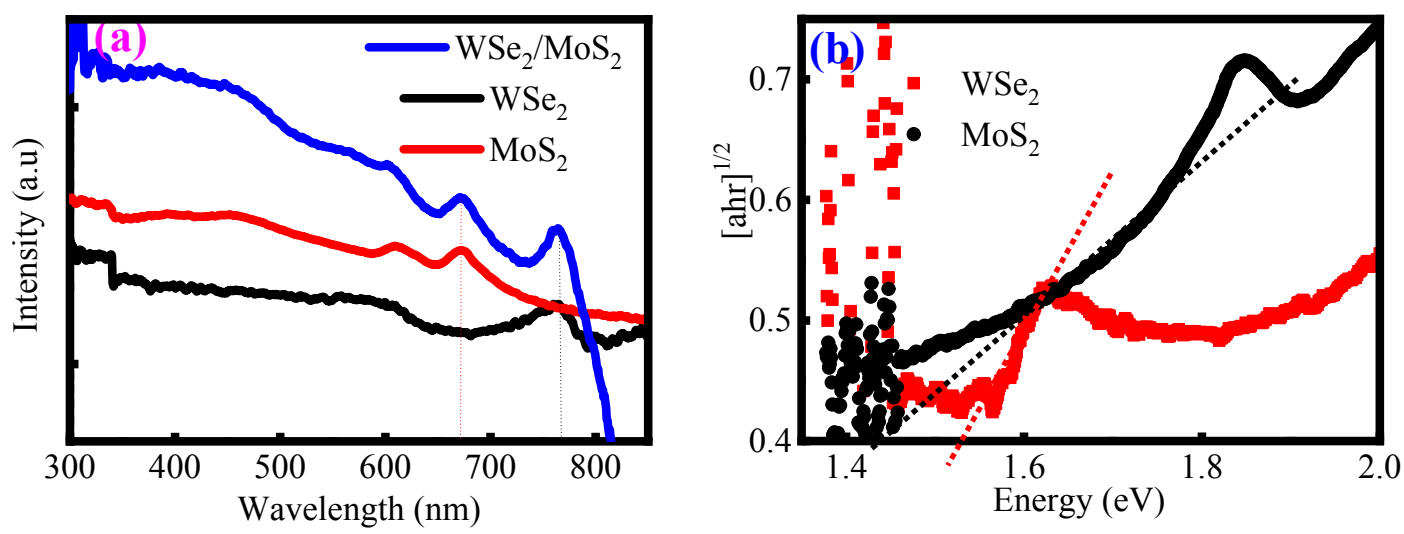

Figure S2 (a) Light absorption of $\mathrm{WSe}_{2} / \mathrm{MoS}_{2}, \mathrm{MoS}_{2}, \mathrm{WSe}_{2}$ in the wavelength ranged from UV to near-IR. (b) the cutoff wavelength of around $800 \mathrm{~nm}$ and $670 \mathrm{~nm}$ arising from the band gap of 1.4 $\mathrm{eV}$ of $\mathrm{WSe}_{2}$ and $1.55 \mathrm{eV}$ of $\mathrm{MoS}_{2}$.

Figure S3 indicate the $n$-type of $\mathrm{MoS}_{2}$ and $p$-type transport of $\mathrm{WSe}_{2}$ with the threshold gate bias of about $-75 \mathrm{~V}$ and $10 \mathrm{~V}$, respectively, which was also proved in the previous reports. The respective carrier concentrations for the pristine channels are estimated $p_{\mathrm{WSe}_{2}}\left(n_{\mathrm{MoS}_{2}}\right)=\mathrm{q}^{-1} \mathrm{C}_{\mathrm{g}}\left|\mathrm{V}_{\mathrm{th}}\right|=$ $5.38 \times 10^{12}\left(7.68 \times 10^{11}\right) \mathrm{cm}^{-2}$, with $\mathrm{C}_{\mathrm{g}}=1.23 \times 10^{-8} \mathrm{~F} \mathrm{~cm}^{-2}, \mathrm{q}=1.6 \times 10^{-19} \mathrm{C}$. The $\mathrm{I}_{\mathrm{DS}}$ of the $n$-type $\mathrm{MoS}_{2} \mathrm{FET}$ is quite high compared to the $\mathrm{I}_{\mathrm{DS}}$ of the $p$-type $\mathrm{WSe}_{2} \mathrm{FET}$, which is attributed to the fact that the carrier density in $\mathrm{MoS}_{2}$ is initially much higher than that in the $\mathrm{WSe}_{2}$ channel, Where typical $n$-type nature of $\mathrm{MoS}_{2}$ and $p$-type nature of $\mathrm{WSe}_{2}$ conduction characteristics are revealed.
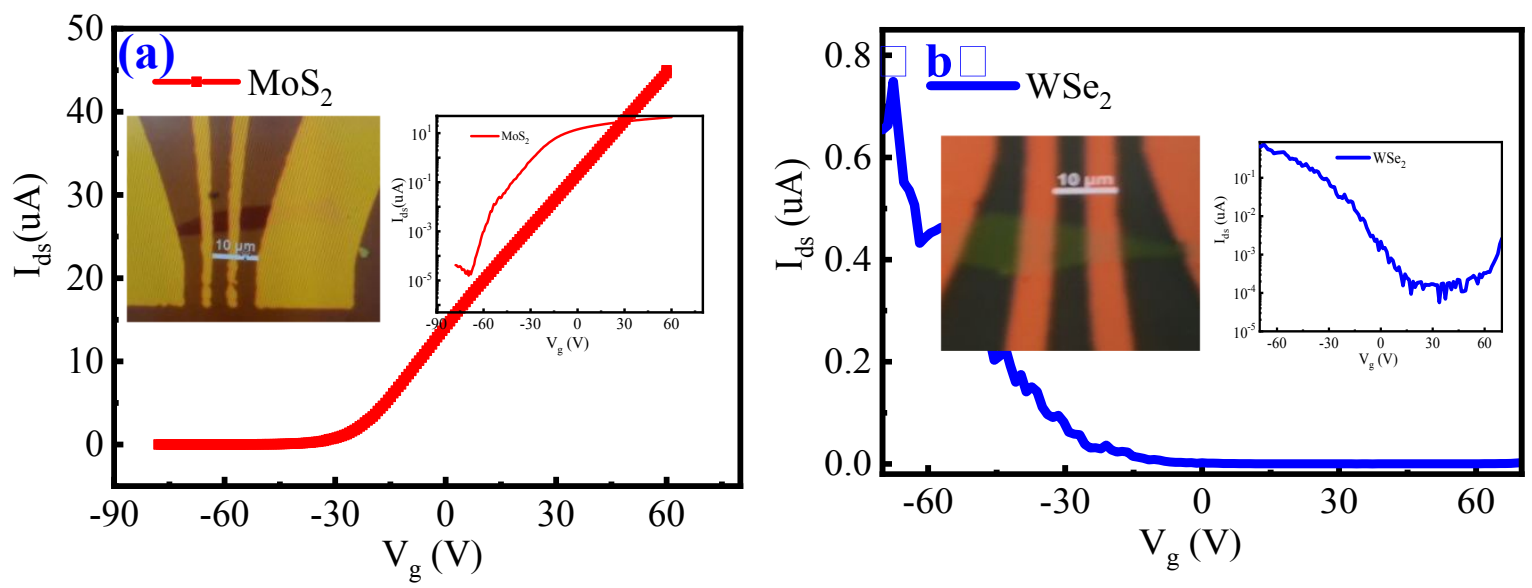

Figure S3 Transport characteristic curves of $\mathrm{WSe}_{2}$ (a) and $\mathrm{MoS}_{2}(\mathrm{~b})$, inset: the photograph of $\mathrm{MoS}_{2}$ device in (a) and $\mathrm{WSe}_{2}$ in (b) 
Figure S4 show the contact between components, and the electrodes is Ohmic. Moreover, the result reveal that the conductive ability of $\mathrm{MoS}_{2}(2 \mathrm{nA})$ is 25 times higher than that of $\mathrm{WSe}_{2}(0.08$ $\mathrm{nA}$ ) at the same $1 \mathrm{~V}$ bias, this is consistent to the transport characteristics (Figure S3), which reveals the fact that the carrier concentration in $n$-type $\mathrm{MoS}_{2}$ is initially much higher than that in the $p$-type $\mathrm{WSe}_{2}$, this is consistent to the previous report. ${ }^{1}$
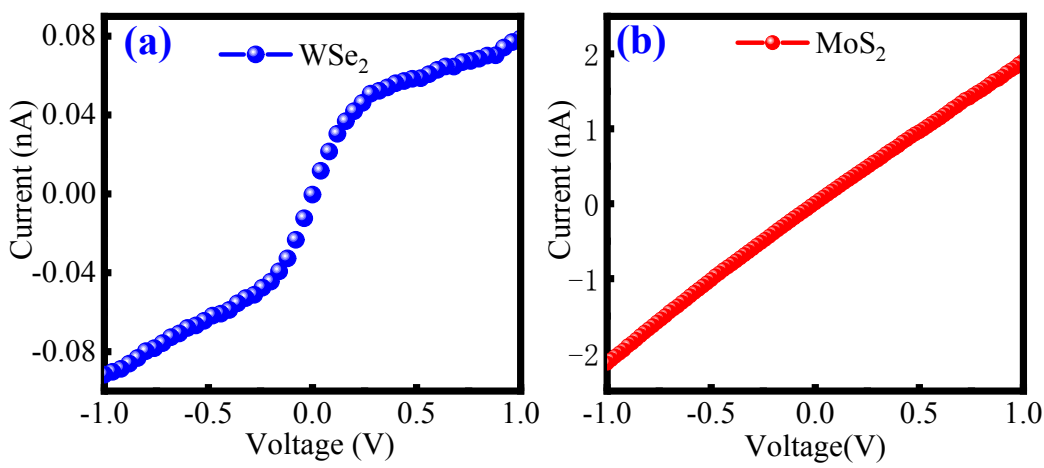

Figure S4 Current-voltage curves of $\mathrm{WSe}_{2}$ (a) and $\mathrm{MoS}_{2}(\mathrm{~b})$

Figure S 5a shows that the dependence of $\mathrm{I}_{\mathrm{ph}}$ \& light power for PVFED and $p n$ junciton device. Figure $\mathrm{S} 5 \mathrm{~b}$ and $\mathrm{c}$ show the schematic diagram of $\mathrm{HBD}$ and $p n$ junction device. The result indicate that the value of photocurrent of PVFED is much larger than that of $p n$ junction device at the same bias, which suggests that the more photo-induced charges are obtained in the PVFED.

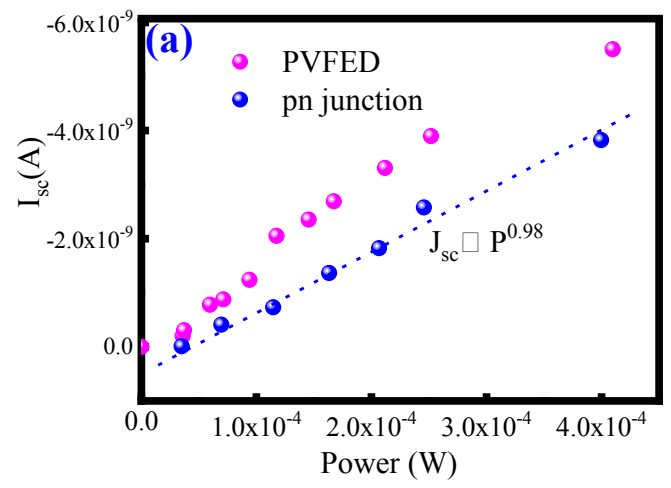

(b)

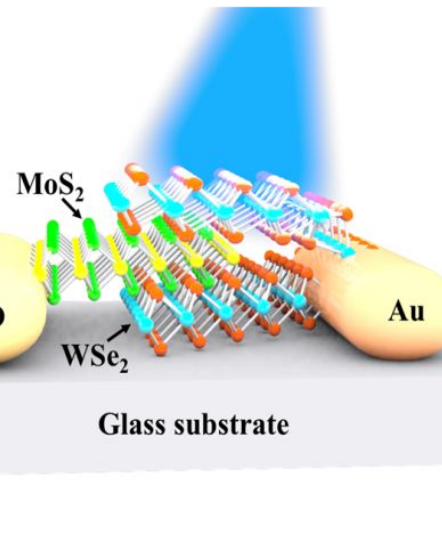

(c)

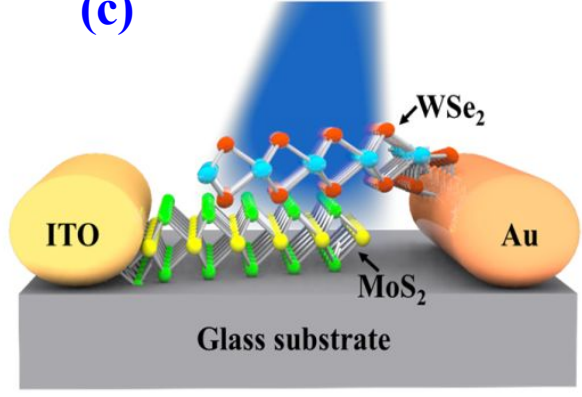

Figure S5 (a) Dependence of $\mathrm{I}_{\mathrm{ph}}$ \& light power for PVFED and pn junction device. (b) HBD schematic diagram. (b) pn junction device schematic diagram 
Figure S 6a shows the photo-electronic performance comparing of PVFED, HBD and $p n$ junction diodes under illuminating. PVFED device exhibits the high signal-to-noise (net photocurrent/ dark current) ratio of $\sim 7.7 * 10^{4}$ at zero bias and $p n$ junction device with $\sim 5.7^{*} 10^{3}$, it enhances an order of magnitude. The high signal-to-noise would promote its application in the weak light photodetection. In addition, the electrical power of PVFED device is also superior shown as Figure S 6b. The current rectification behavior of the PVFED is better that of traditional $p n$ diode with the high rectification $\left(10^{3}\right.$ at $\left.\pm 1 \mathrm{~V}\right)$. The ideality factor is fitted to be 1.15 , that is low compared to that of $p n$ junction (2.99) at the same conditions. This tendency was also obtained in the previous report, in which the ideality factor of pnp junction is close to $1 .^{2}$
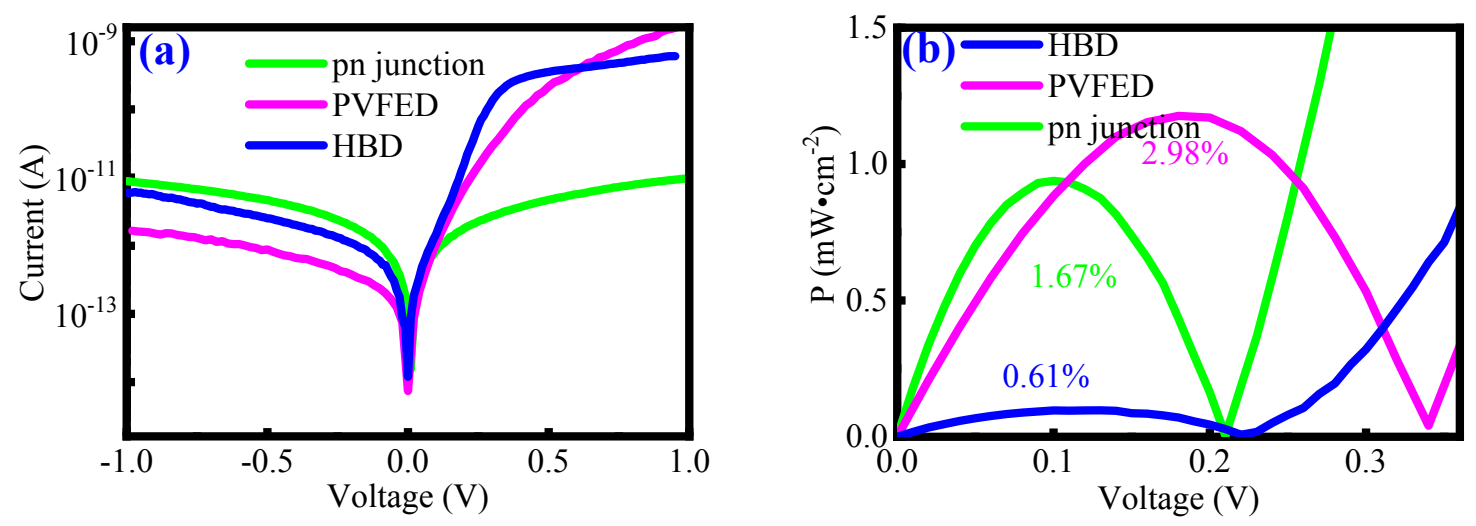

Figure S6 Photo-electronic performance comparing of PVFED, HBD and $p n$ junction diodes. (a) Output characteristics in LnI-V in the dark. (b) Electrical power.

Figure S7 shows the photovoltaic characteristics of the bottom and top $\mathrm{WSe}_{2}$ floating on $\mathrm{MoS}_{2} / \mathrm{WSe}_{2}$ device. The result indicate that the $\mathrm{J}_{\mathrm{sc}}$ was slightly lower than that of the bottom floating device, since the top layer $\mathrm{WSe}_{2}$ receives more light, and the photogenerated carriers do not participate in the recirculating due to not connected with electrode.

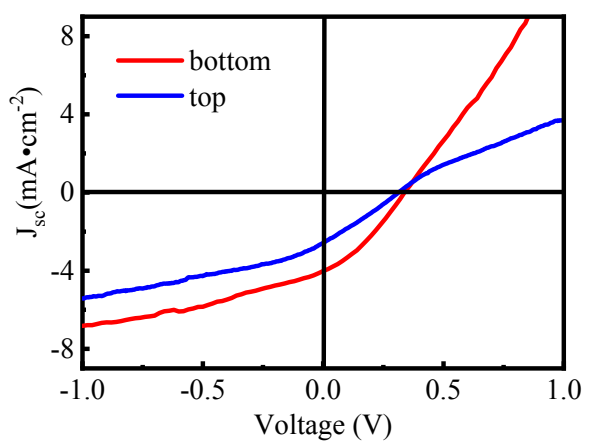

Figure S7 I-V curves of top floating and bottom floating device under white light illuminating 
Figure S 8 shows the stability of device to store in air for six weeks, and the results were repeatable without any observable ambience induced deterioration.

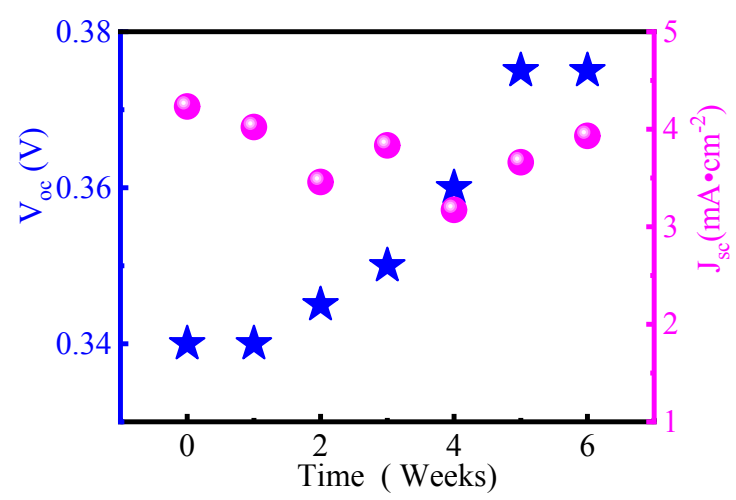

Figure S8 the diagraph of PVFED stability test for photovoltaics

Table S1 Photovoltaic parameters of PVFED, HBD, $p n$ junction diode

\begin{tabular}{lllll|l}
\hline Type (Junction) & $\mathrm{V}_{\mathrm{oc}}(\mathrm{V})$ & $\mathrm{J}_{\mathrm{sc}}\left(\mathrm{mA} \cdot \mathrm{cm}^{-2}\right)$ & $\mathrm{J}_{0}\left(\mathrm{nA} \cdot \mathrm{cm}^{-2}\right)$ & $\eta(\%)$ & Effective area $\left(\mathrm{um}^{2}\right)$ \\
\hline$p n$ & 0.21 & 0.613 & 107.5 & 1.67 & 148.8 \\
PVFED & 0.34 & 4.1 & 53.2 & 2.98 & 133.3 \\
HBD & 0.22 & 1.94 & 1203.1 & 0.61 & 109.2 \\
\hline
\end{tabular}

Figure $\mathrm{S} 9 \mathrm{a}$ shows that $\mathrm{R}$ is changed as the external bias is changed, and the $\mathrm{R}$ value of the device at zero or negative bias is significantly higher than that at the positive bias. This tendency is well agreed with the behaviors of the common $p n$ device, which implies that the device of PVFED operates mainly at the photovoltaic diodes mode, not transistor mode. As shown in Figure S 9b and $\mathrm{c}$, the responsivity and detectivity are almost unchanged with the increase of light power. The results imply that there is the presence of the field effect in the PVFED, which could originate from the photovoltage of floated vdWHs. 

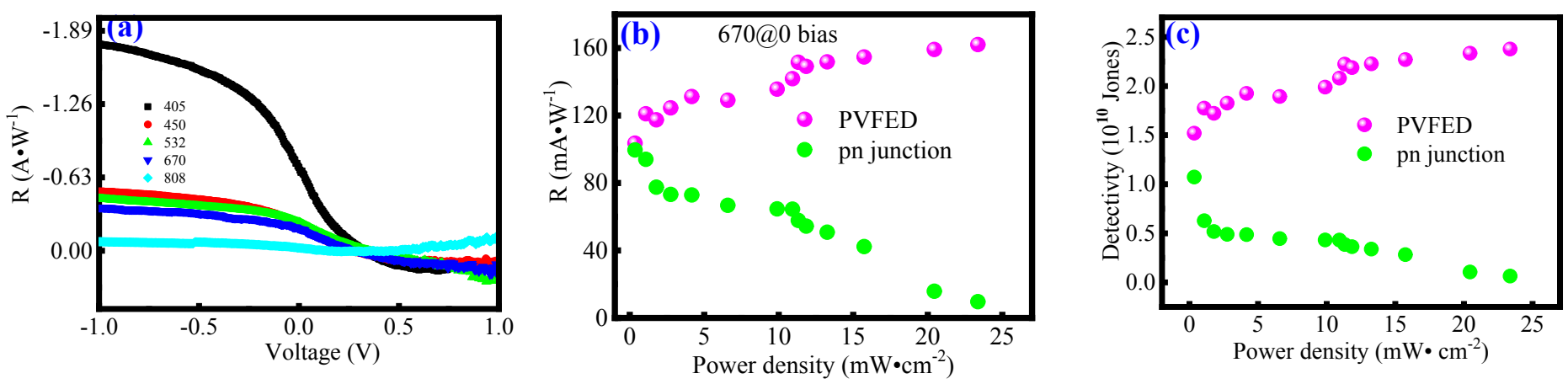

Figure S9 (a) Responstivity of PVFED under the different wavelength illuminating at different bias from $-1 \mathrm{~V}$ to $1 \mathrm{~V}$. Comparation of detection performance for PVFED and $p n$ junction device under $670 \mathrm{~nm}$ laser illuminating with the different light power, (b) Responsitivity and (c) Detectivity.

Figure $\mathrm{S} 10 \mathrm{a}$ and $\mathrm{b}$ show the benchmarking the parameters of photodetectors, the comparable rresults indicate that the prominent performance of PVFED includes the high responsivity, detectivity and fast response speed, which indicate that the PVFED has a great potential in the next generation self-powered photoelectric devices.
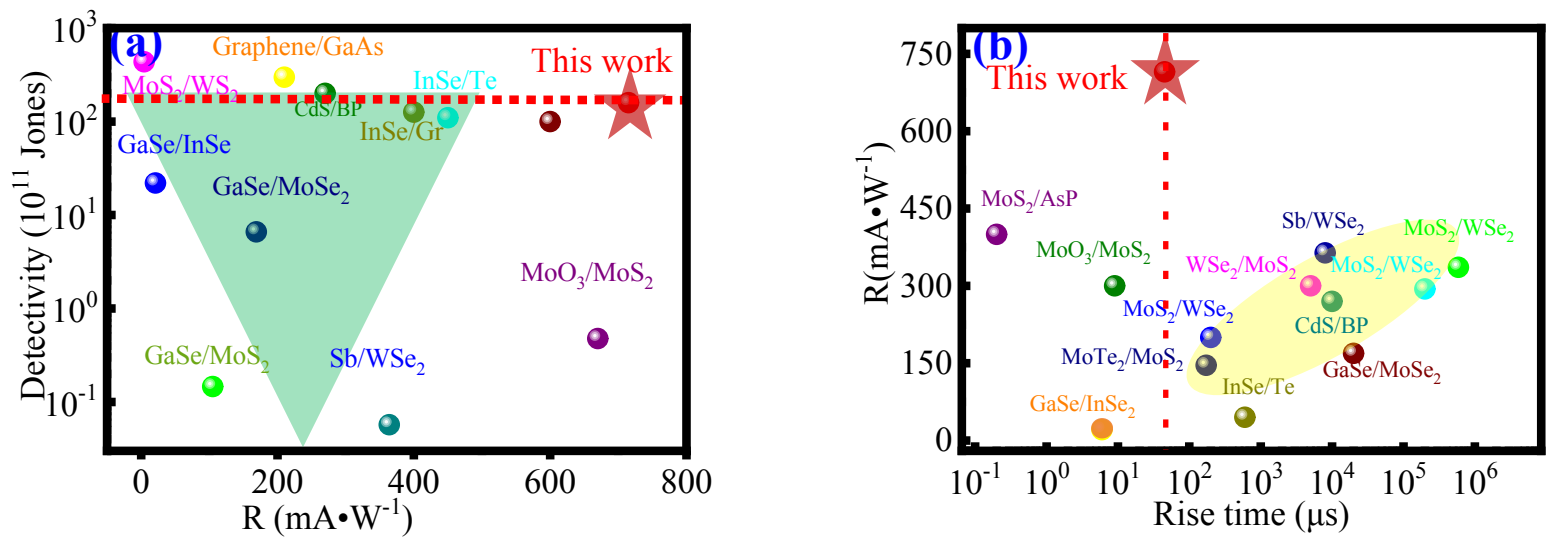

Figure S10 Benchmarking the parameters of photodetector in (a) responsivity and detectivity, (b) the response time and the responsitivity. 
Table S2 Summary of vdWHs photodetectors merits without any external bias

\begin{tabular}{|c|c|c|c|c|c|}
\hline vdWHs & $\lambda(\mathrm{nm})$ & $\mathrm{R}\left(\mathrm{mA} \cdot \mathrm{W}^{-1}\right)$ & $\mathrm{D}$ (Jones) & $\mathrm{t}_{\mathrm{r}}(\mu \mathrm{s})$ & Refer \\
\hline $\mathrm{MoS}_{2} / \mathrm{WSe}_{2} / \mathrm{MoS}_{2}$ & 405 & 715 & $1.59 \times 10^{13}$ & 45 & This work \\
\hline $\mathrm{MoSe}_{2} / \mathrm{WSe}_{2}$ & 520 & 336 & & 589000 & {$\left[{ }^{3}\right]$} \\
\hline $\mathrm{MoS}_{2} / \mathrm{WSe}_{2}$ & 405 & 110 & & & {$\left[{ }^{4}\right]$} \\
\hline $\mathrm{MoS}_{2} / \mathrm{WSe}_{2}$ & 532 & 200 & & 200 & {$\left[{ }^{5}\right]$} \\
\hline $\mathrm{MoS}_{2} / \mathrm{WSe}_{2}$ & blue & 294 & & 200000 & {$\left[{ }^{6}\right]$} \\
\hline $\mathrm{MoS}_{2} / \mathrm{WSe}_{2}$ & 590 & 11 & & & {$\left[{ }^{7}\right]$} \\
\hline $\mathrm{WSe}_{2} / \mathrm{MoS}_{2}$ & 450 & 300 & & 5 & {$\left[{ }^{8}\right]$} \\
\hline $\mathrm{WSe}_{2} / \mathrm{MoS}_{2} / \mathrm{BN}$ & 532 & 284.6 & & & {$\left[{ }^{9}\right]$} \\
\hline $\mathrm{GeSe} / \mathrm{MoS}_{2}$ & 532 & 105 & $1.46 \times 10^{10}$ & & {$\left[{ }^{10}\right]$} \\
\hline$p$-GaSe/ $n-\mathrm{InSe}$ & 410 & 21 & $2.2 \times 10^{12}$ & 5.97 & {$\left[{ }^{11}\right]$} \\
\hline InSe-Te & 300 & 450 & $1.1 \times 10^{13}$ & 600 & {$\left[{ }^{12}\right]$} \\
\hline $\mathrm{MoS}_{2}-\mathrm{WS}_{2}$ & 532 & 4.36 & $4.36 \times 10^{13}$ & 4 & {$\left[{ }^{13}\right]$} \\
\hline graphene/GaAs & 405 & 210 & $2.98 \times 10^{13}$ & & {$\left[{ }^{14}\right]$} \\
\hline $\mathrm{MoTe}_{2} / \mathrm{MoS}_{2}$ & 450 & 146 & & 172 & {$\left[{ }^{15}\right]$} \\
\hline $\mathrm{InSe} / \mathrm{Gr}$ & 532 & 400 & $1.26 \times 10^{13}$ & 200 & {$\left[{ }^{16}\right]$} \\
\hline $\mathrm{GaSe} / \mathrm{MoSe}_{2}$ & 532 & 169 & $6.6 \times 10^{11}$ & 20 & {$\left[{ }^{17}\right]$} \\
\hline $\mathrm{MoS}_{2} / \mathrm{AsP}$ & 520 & 300 & & 9 & {$\left[{ }^{18}\right]$} \\
\hline $\mathrm{MoO}_{3} / \mathrm{MoS}_{2}$ & 600 & 670 & $4.77 \times 10^{10}$ & & {$\left[{ }^{19}\right]$} \\
\hline $\mathrm{Gr} / \mathrm{WSe}_{2} / \mathrm{Gr}$ & 735 & 600 & $10^{13}$ & 8 & {$\left[{ }^{20}\right]$} \\
\hline $\mathrm{CdS} / \mathrm{BP}$ & 450 & 270 & $2 \times 10^{13}$ & 10 & {$\left[{ }^{21}\right]$} \\
\hline $\mathrm{Sb} / \mathrm{WSe}_{2}$ & 520 & 364 & $5.7 \times 10^{9}$ & 8 & {$\left[{ }^{22}\right]$} \\
\hline $\mathrm{BP} / \mathrm{MoS}_{2}$ & 633 & 418 & & & {$\left[{ }^{23}\right]$} \\
\hline
\end{tabular}

\section{REFERENCES}

1. Lee, J. B.; Lim, Y. R.; Katiyar, A. K.; Song, W.; Lim, J.; Bae, S.; Kim, T. W.; Lee, S. K.; Ahn, J. H. Direct Synthesis of a Self-Assembled WSe $2 / \mathrm{MoS}_{2}$ Heterostructure Array and Its Optoelectrical Properties. Advanced Materials. 2019, 31, 1904194.

2. Choi, W.; Akhtar, I.; Kang, D.; Lee, Y.-j.; Jung, J.; Kim, Y. H.; Lee, C.-H.; Hwang, D. J.; Seo, Y. Optoelectronics of Multijunction Heterostructures of Transition Metal Dichalcogenides. Nano Letters. 2020, 20, 1934-1943.

3. Patel, A. B.; Chauhan, P.; Patel, K.; Sumesh, C. K.; Narayan, S.; Patel, K. D.; Solanki, G. K.; Pathak, V. M.; Jha, P. K.; Patel, V. Solution-Processed Uniform $\mathrm{MoSe}_{2}-\mathrm{WSe}_{2}$ Heterojunction Thin Film on Silicon Substrate for Superior and Tunable Photodetection. ACS Sustainable Chemistry \& Engineering. 2020, 8, 4809-4817.

4. Hyo SunLee, J., WooyoungShim,SeongilIm, Do KyungHwang. 2D WSe $-\mathrm{MoS}_{2}$ van der Waals Heterojunction Photodiode for Visible-Near Infrared Broadband Detection. Applied Physics Letter. 2018, 113, 163102

5. Yang, S.; Cha, J.; Kim, J. C.; Lee, D.; Huh, W.; Kim, Y.; Lee, S. W.; Park, H. G.; Jeong, H. Y.; Hong, S.; Lee, G. H.; Lee, C. H. Monolithic Interface Contact Engineering to Boost Optoelectronic Performances of 2D Semiconductor Photovoltaic Heterojunctions. Nano Letters. 2020, 20, 2443-2451.

6. Jeon, P. J.; Min, S.-W.; Kim, J. S.; Raza, S. R. A.; Choi, K.; Lee, H. S.; Lee, Y. T.; Hwang, D. K.; Choi, H. J.; Im, S. Enhanced Device Performances of $\mathrm{WSe}_{2}-\mathrm{MoS}_{2}$ van der Waals Junction $p-n$ Diode by Fluoropolymer Encapsulation. Journal of Materials Chemistry C. 2015, 3, 2751-2758.

7. Furchi, M. M.; Pospischil, A.; Libisch, F.; Burgdorfer, J.; Mueller, T. Photovoltaic Effect in an Electrically Tunable van der Waals Heterojunction. Nano Letters. 2014, 14, 4785-91.

8. Deng, W.; You, C.; Chen, X.; Wang, Y.; Li, Y.; Feng, B.; Shi, K.; Chen, Y.; Sun, L.; Zhang, Y. High-Performance Photodiode Based on Atomically Thin $\mathrm{WSe}_{2} / \mathrm{MoS}_{2}$ Nanoscroll Integration. Small.2019, 15, 1901544.

9. Huang, X.; Feng, X.; Chen, L.; Wang, L.; Tan, W. C.; Huang, L.; Ang, K.-W. Fabry-Perot Cavity Enhanced Light-Matter Interactions in Two-Dimensional van der Waals Heterostructure. Nano Energy. 2019, 62, 667-673.

10. Xin, Y.; Wang, X.; Chen, Z.; Weller, D.; Wang, Y.; Shi, L.; Ma, X.; Ding, C.; Li, W.; Guo, S.; Liu, R. Polarization-Sensitive Self-Powered Type-II GeSe/ $\mathrm{MoS}_{2}$ van der Waals Heterojunction Photodetector. ACS Applied Materials \& Interfaces. 2020, 12, 15406-15413.

11. Yan, F.; Zhao, L.; Patane, A.; Hu, P.; Wei, X.; Luo, W.; Zhang, D.; Lv, Q.; Feng, Q.; Shen, C.; Chang, K.; Eaves, L.; Wang, K. Fast, 
Multicolor Photodetection with Graphene-Contacted $p$-GaSe/n-InSe van der Waals Heterostructures. Nanotechnology. 2017, $28,27 \mathrm{LT01}$.

12. Qin, F.; Gao, F.; Dai, M.; Hu, Y.; Yu, M.; Wang, L.; Feng, W.; Li, B.; Hu, P. Multilayer InSe-Te van der Waals Heterostructures with an Ultrahigh Rectification Ratio and Ultrasensitive Photoresponse. ACS Applied Materials \& Interfaces. 2020, 12, 37313-37319.

13. Wu, W.; Zhang, Q.; Zhou, X.; Li, L.; Su, J.; Wang, F.; Zhai, T. Self-Powered Photovoltaic Photodetector Established on Lateral Monolayer $\mathrm{MoS}_{2}-\mathrm{WS}_{2}$ Heterostructures. Nano Energy. 2018, 51, 45-53.

14. Lu, Y.; Feng, S.; Wu, Z.; Gao, Y.; Yang, J.; Zhang, Y.; Hao, Z.; Li, J.; Li, E.; Chen, H.; Lin, S. Broadband Surface Plasmon Resonance Enhanced Self-Powered Graphene/GaAs Photodetector with Ultrahigh Detectivity. Nano Energy 2018, 47, 140-149.

15. Li, S.; He, Z.; Ke, Y.; Guo, J.; Cheng, T.; Gong, T.; Lin, Y.; Liu, Z.; Huang, W.; Zhang, X. Ultra-Sensitive Self-Powered Photodetector Based on Vertical MoTe $2 \mathrm{MoS}_{2}$ Heterostructure. Applied Physics Express. 2020, 13, 015007.

16. Dai, M.; Chen, H.; Wang, F.; Long, M.; Shang, H.; Hu, Y.; Li, W.; Ge, C.; Zhang, J.; Zhai, T.; Fu, Y.; Hu, P. Ultrafast and Sensitive Self-Powered Photodetector Featuring Self-Limited Depletion Region and Fully Depleted Channel with van der Waals Contacts. ACS Nano. 2020, 14, 9098-9106.

17. Ning J.; Zhou Y.; Zhang J.; Lu W.; Dong J.; Yan C.; Wang D.; Shen X.; Feng X.; Zhou H.; Hao Y. Self-Driven Photodetector Based on a GaSe/MoSe 2 Selenide van der Waals Heterojunction with the Hybrid Contact. Applied Physics Letters. 2020, 117, 163104.

18. Wu, F.; Li, Q.; Wang, P.; Xia, H.; Wang, Z.; Wang, Y.; Luo, M.; Chen, L.; Chen, F.; Miao, J.; Chen, X.; Lu, W.; Shan, C.; Pan, A.; Wu, X.; Ren, W.; Jariwala, D.; Hu, W. High Efficiency and Fast van der Waals Hetero-Photodiodes with a Unilateral Depletion Region. Nature Communications. 2019, 10, 4663.

19. Zhang, R.; Ma, X.; An, C.; Zhang, D.; Sun, D.; Hu, X.; Liu, J. Self-Powered Photodetector Based on Vertical $\mathrm{MoO}_{3} / \mathrm{MoS}_{2}$ Hetero-Structure with Gate Tunable Photo-Response. 2D Materials. 2019, 6, 035033.

20. Wang, T.; Andrews, K.; Bowman, A.; Hong, T.; Koehler, M.; Yan, J.; Mandrus, D.; Zhou, Z.; Xu, Y.-Q. High-Performance WSe ${ }_{2}$ Phototransistors with 2D/2D Ohmic Contacts. Nano Letters. 2018, 18, 2766-2771.

21. Zubair, M.; Zhu, C.; Sun, X.; Liu, H.; Zheng, B.; Yi, J.; Zhu, X.; Li, D.; Pan A. Record High Photoresponse Observed in CdS-Black Phosphorous van der Waals Heterojunction Photodiode. Science China Materials. 2020, 63, 1570-1578.

22. Liu, X.; Sun, G.; Chen, P.; Liu, J.; Zhang, Z.; Li, J.; Ma, H.; Zhao, B.; Wu, R.; Dang, W.; Yang, X.; Dai, C.; Tang, X.; Chen, Z.;

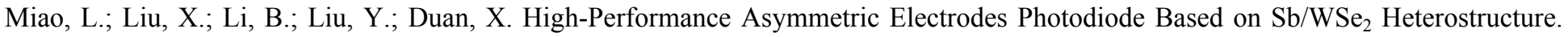
Nano Research. 2018, 12, 339-344.

23. Deng, Y.; Lou, Z.; Conrad, N. J.; Liu, H.; Gong, Y.; Najmaei, S.; Ajayan, P. M.; Lou, J.; Xu, X.; Ye, P. D. Black Phosphorus-Monolayer $\mathrm{MoS}_{2}$ van der Waals Heterojunction $p-n$ Diode. ACS Nano. 2014, 8, 8292-8299. 